Bulletin d'Histoire Contemporaine de l'Espagne

$50 \mid 2016$

Les intellectuels en Espagne, de la dictature à la démocratie (1939-1986)

\title{
Los intelectuales, entre revolución, democracia y consumo cultural en los años sesenta
}

Les intellectuels entre la révolution, la démocratie et la consommation culturelle des années soixante

The intellectuals between the revolution, the democracy and the cultural consumption of the sixties

\section{Carles Santacana}

\section{OpenEdition \\ Journals}

\section{Edición electrónica}

URL: http://journals.openedition.org/bhce/532

DOI: 10.4000/bhce.532

ISSN: 1968-3723

Editor

Presses Universitaires de Provence

Edición impresa

Fecha de publicación: 1 diciembre 2016

Paginación: 75-84

ISSN: 0987-4135

Referencia electrónica

Carles Santacana, « Los intelectuales, entre revolución, democracia y consumo cultural en los años sesenta », Bulletin d'Histoire Contemporaine de l'Espagne [En línea], 50 | 2016, Publicado el 09 octubre 2018, consultado el 18 septiembre 2020. URL : http://journals.openedition.org/bhce/532 ; DOI https://doi.org/10.4000/bhce.532 


\section{Los intelectuales, entre revolución, democracia y consumo cultural en los años sesenta}

\section{Carles SANTACANA}

Universidad de Barcelona

$\mathrm{H}$ ace unos años Glicerio Sánchez-Recio reunió a un grupo de especialistas para analizar los años sesenta ${ }^{1}$ desde diferentes ángulos, pero con un común denominador, que era la percepción de los cambios. La noción de cambio y sus ritmos es una cuestión determinante que atravesó la sociedad española en esa década, en gran parte porque ese era el significado que tenían esos años en el mundo occidental, del cual formaba parte a pesar de los denodados intentos de la dictadura franquista por minimizarlo. Son muchas las imágenes que reflejan esa peculiar dinámica, pero puestos a memorizar ahora un par de ejemplos que tienen relación con las pautas culturales en su sentido más antropológico resultaría bastante evidente la de los componentes de The Beatles bajando de la escalerilla del avión tocados con una montera. Al mismo tiempo, otra imagen documenta el reverso de la moneda, cuando a principios de los sesenta guardias civiles con su característico tricornio llamaban la atención a turistas extranjeras ataviadas con bikinis. Son dos imágenes en que aparecían con principal protagonismo la juventud, un actor social que no quería actuar subordinadamente y tomaba una gran relevancia.

Empiezo proponiendo este contraste iconográfico en una cuestión que puede parecer extemporánea si vamos a tratar sobre los intelectuales, al ampliar el foco a los cambios culturales, pero que parece una referencia oportuna para llamar la atención a la necesaria vinculación entre las preocupaciones y la actitud de los intelectuales en un momento en que es el conjunto de la sociedad el que vive inmerso en una situación de cambio. Por lo demás, se trata de una de las mutaciones más profundas que ha vivido históricamente la sociedad española en todos los ámbitos estructurales, desde la economía a ingentes migraciones, el fin de la sociedad agraria en muchas comunidades y la diversificación industrial, la caída definitiva del analfabetismo y la irrupción de una sociedad de consumo que chocaba culturalmente, ya que seguía a una dura postguerra que había significado un terrible retroceso.

Así pues, cambio y novedad son sin duda las características que marcan de manera más clara la intervención de los intelectuales en la España de los sesenta. Viven en un contexto de enorme transformación social, en una sociedad que progresivamente cada vez tiene menos que ver con la de la postguerra en ningún sentido, excepto en la continuidad de la dictadura, cuestión que naturalmente no pretendemos minusvalorar, pero que no es el único elemento con poder explicativo. Es significativo que algunos de los protagonistas ya vislumbraran esa idea muy tempranamente. Uno de los intelectuales clave de este

1 Glicerio Sánchez Recio, Eppure si muove. La percepción de los cambios en España (1959-1976), Madrid, Biblioteca Nueva, 2008. 
período, omnipresente en todo tipo de iniciativas y plataformas, exponente de los jóvenes que abandonaron el falangismo para reformular una ética democrática, José Luis López Aranguren, escribía en 1963 en la presentación de la colección de libros Tiempo de España:

Precisamente, característica importante de lo que está ocurriendo en nuestro país y que perciben bien los observadores perspicaces es que, por debajo de su corteza política, la realidad social está sufriendo rápidas y profundas mutaciones que, llegado el momento, acarrearán otras más espectaculares. Asistimos, nos guste o no, a una desintegración interna de heredadas estructuras económicas y sociales, que se mantienen por imposición o por inercia, y hasta las mismas pautas de comportamiento interpersonal entran en crisis. Creo que quien, por debajo de la rigidez no perciba la fluidez, no entiende casi nada de lo que entre nosotros está ocurriendo².

En esta cita de Aranguren aparece una percepción condensada de todo lo que estaba ocurriendo, o quizás también de lo que a él le gustaría que fuese cierto, ya que en la situación que se vivía bien podía ser que se confundiera el deseo con la realidad; en definitiva, la necesidad vital para un intelectual crítico de dar carta de naturaleza a cualquier atisbo de cambio de la realidad oficial franquista.

\section{Los grandes condicionamientos: en el mundo, a pesar del aislamiento}

En cualquier caso, el cambio y la novedad se producían en todo el mundo occidental, desde las independencias en Asia y África, con la emergencia del Tercer Mundo y su lectura antiimperialista y en gran parte antinorteamericana, un país que tomaba un enorme protagonismo como elemento de referencia. De hecho, los Estados Unidos son por vez primera un eje de referencia fundamental tanto desde la perspectiva cultural como también política, una perspectiva novedosa para la intelectualidad española ${ }^{3}$, más allá de los pactos de 1953. También es necesario tener en cuenta el auge del marxismo más allá de su traducción estrictamente política, sino sobre todo por la influencia que muestra en el mundo cultural y académico europeo, al que se suma también el auge de la contracultura, de la que harán gala algunos que viven muy de cerca las experiencias californianas, como Luis Racionero, o en el más cercano mayo francés. Descolonización, marxismo, contracultura, etc. evocan naturalmente un peso determinante de valores y propuestas asociadas genéricamente con las izquierdas, que de esa manera determinan el eje de los debates del momento.

Además, la institución que en España se vinculaba más fácilmente con la reacción conservadora, la Iglesia católica, justamente en esos momentos plantea una revisión desde la jerarquía sobre su papel en la sociedad. Ese es el sentido último del Concilio Vaticano II (1962-1965), que espolea el debate teórico en todo el mundo católico, ya que pone sobre la mesa institucional lo que algunos movimientos católicos empezaron a plantear de forma minoritaria en el período de entreguerras y había tomado más cuerpo en los años cincuenta. En un país oficialmente católico el hecho mismo que se abriera un debate en el catolicismo internacional ofrecía posibilidades inéditas hasta el momento y podía abrir una vía de agua en la pétrea rigidez del catolicismo oficial ${ }^{4}$. Por último, y en un terreno mucho más

2 José Luis Lopez ArAnguren, «Presentación» al libro colectivo Libertady organización, Madrid, Ínsula, 1963, p. 4.

3 Recientemente la historiografía española ha tomado interés en el análisis de esta cuestión. Una visión de conjunto en Antonio Niño (ed.), La ofensiva culturale norteamericana durante la Guerra Fria, Ayer, $\mathrm{n}^{\circ} 75,2009$.

4 Hilari RAguer, Réquiem por la cristiandad. El Concilio Vaticano II y su impacto en España, Barcelona, Peninsula, 2006. 
pragmático, la firma del Tratado de Roma en 1957 daba carta de naturaleza y cobertura institucional a un proceso mucho más ambicioso, que iba mucho más allá de la alianza económica, y que tenía un carácter político, en el sentido que el europeísmo se identificaba con la democracia y la cobertura institucional europea podía ser utilizada en un sentido crítico con la dictadura.

Aunque podamos recorrer a precedentes o fases previas, todos estos planteamientos emergen con fuerza en los años sesenta y de manera prácticamente simultánea, de manera que suponen un nuevo escenario en el tránsito de las ideas que al franquismo le resulta difícil esconder, y que sólo podrá retrasar o amortiguar, pero no eliminar. Todo ello se sobrepone, no podemos olvidarlo, a la continuidad de la Guerra Fría, que por contraste es el gran elemento de continuidad con la década anterior.

\section{Una gran transformación social}

Como ya se ha señalado, la década está marcada por una enorme transformación estructural de la sociedad ${ }^{5}$. Dicho telegráficamente, aparece una clase media mínimamente consistente ${ }^{6}$, se activan nuevos hábitos sociales que nos hablan de cambios de mentalidad y procesos de aprendizaje cultural, formas de escolarización mucho más masivas que en el período anterior, práctica desaparición del analfabetismo, etcétera. De hecho, hace años Pierre Vilar afirmó que esos años son los de la verdadera revolución industrial en España. Son muchos los items que muestran esa transformación del país real, que incluso desborda las previsiones oficiales, y que lleva aparejada la aparición de pautas de una sociedad de consumo $^{7}$. Se trata de un país real dinámico, en que aparecen nociones tan sofisticadas como el marketing, y en el que no podemos obviar la fortaleza de los medios de comunicación de masas, y específicamente de la televisión, un aspecto que promoverá grandes discusiones entre periodistas e intelectuales, con la gran figura de Manuel Vázquez Montalbán en su vertiente de fino analista, a la que nos referiremos más adelante. De otro lado, la urbanización definitiva del país es un dato muy relevante a todos estos efectos, ya que en esos años las diferencias entre la sociedad urbana y el mundo rural eran muy acusadas y tenían una gran trascendencia en clave de comportamientos sociales y culturales. Si en un sentido el mundo urbano significaba mayores posibilidades de acceso a bienes y discursos culturales más diversificados, sin olvidar los límites que seguía ejerciendo el poder; en el mundo rural la capacidad de control social era notablemente mayor, y podía seguir con pautas más cercanas a las desarrolladas en la década anterior. En este sentido, las evidentes transformaciones motivadas por el abandono del mundo rural, las grandes corrientes migratorias y la urbanización e industrialización no deben ser observadas puramente como datos estructurales que empiezan y acaban en sí mismos, sino como elementos de cambio con grandes repercusiones en los mecanismos de reproducción cultural y de conflicto entre la conservación de las pautas implantadas por la dictadura en la postguerra y las fisuras que podrían abrirse.

5 Véase, en este sentido, los diversos informes sociológicos publicados en la época, especialmente los editados por FOESSA, que permiten evaluar los aspectos más objetivables, pero también las percepciones culturales e ideológicas de la población.

6 Una aproximación en José SÁNCHEZ, «La pujanza de las clases medias», en Glicerio SÁNCHEZ, op. cit., p. 31-51.

7 No deja de ser significativo que en 1966, en el primer número de Anales de Sociología, uno de sus artículos se titulase «¿Es España sociedad de consumo de masas?». 


\section{El pasado endógeno más inmediato}

Obviamente no todo comenzó en los años sesenta, y sería imprescindible anotar algunas cuestiones sobre las disputas entre los intelectuales salidos del mundo oficial, las querellas entre opusdeístas y falangistas, o los debates sobre el mantenimiento de la tradición liberal. No entramos en estas interesantes cuestiones, aunque es imprescindible una mínima referencia, ya que la interpretación de lo que sucedió en los años de la posguerra afecta directamente a lo más sustancial de lo que sucedería ahora. En este aspecto, y siguiendo a Santos Juliá,

resulta difícil entender contenidos fundamentales de la cultura política española de los años sesenta y setenta si no se identifica el propósito que guió su política cultural en aquellas dos ocasiones (se refiere a 1940 y 1951-56): no es baladí para la configuración de valores de una sociedad que vio arrasada sus diversas tradiciones culturales, que la cultura política democrática en España haya sido elaborada y extendida, entre otros agentes, por un grupo de intelectuales que habían sido fascistas en su juventud y que durante un largo trecho de su madurez creyeron posible una integración de los vencidos en el bando de los vencedores ${ }^{8}$.

Es decir, que no podremos interpretar el desarrollo de una cultura democrática como el simple y lógico resurgir de una cultura liberal que en realidad habría sido gestionada por falangistas. En este sentido, el papel en los años sesenta de algunos conspicuos autores, como Dionisio Ridruejo, no pueden descansar en valoraciones equivocadas de sus propuestas de la etapa anterior ${ }^{\circ}$. Este caso particular ilustra un error extendido, una especie de aceleración histórica que busca convertir en demócratas lo más remotamente posible a todos los que estuvieron inicialmente encuadrados cómodamente en el régimen. Más allá de este mínimo apunte mirando hacia atrás, sí que llamamos la atención precisamente sobre el cambio de escenario, y sobre la progresiva desaparición de las pugnas de los cincuenta, que van perdiendo sentido y que tenían una clave muy específicamente española (el ser de España, comprensivos y excluyentes, el papel del exilio...) y que ahora cambian notablemente, impelidas entre otras cuestiones por la fuerza que toman los debates internacionales. De la misma manera también identificamos un cambio generacional, con la incorporación de muchos jóvenes, por ejemplo los estudiantes que rápidamente toman un protagonismo entre los sectores críticos con el régimen ${ }^{10}$. Y tampoco podemos obviar la posibilidad de utilizar nuevos instrumentos de intervención cultural, ámbito en el que debemos destacar revistas culturales y editoriales ${ }^{11}$, que asumen una gran centralidad en el debate cultural, con cabeceras de enorme relevancia, como Triunfo y Cuadernos para el Diálogo, ésta última base también de una importante editorial ${ }^{12}$, y que contraponía el concepto de diálogo a la retórica oficial de la paz y la victoria.

8 Santos Julia, Historia de las dos Españas, Madrid, Taurus, 2004, p. 406

9 Véase una correcta apreciación de su trayectoria en Francisco Morente, Dionisio Ridruejo. Del fascismo al antifranquismo, Madrid, Sintesis, 2006.

10 Una sintesis reciente sobre el movimiento estudiantil es la de Elena HernÁNDEZ, Miguel Ángel Ruiz y Marc Baldo, Estudiantes contra Franco (1939-1975). Oposición politica y movilización juvenil, Madrid, La Esfera de los Libros, 2007.

11 Una aproximación a ese complejo mundo en Xavier Moret, Tiempo de editores. Historia de la edición en España (1939-1975), Barcelona, Destino, 2002.

12 Asi como Triunfo ha generado más libros de memorias que estudios académicos, en el caso de Cuadernos es muy útil el estudio de Javier Muñoz Soro, Cuadernos para el Diálogo (1963-1976). Una historia cultural del segundo franquismo, Madrid, Marcial Pons, 2006. 


\section{Los grandes ejes del período}

Situados ya plenamente en los sesenta (no podemos entrar en el breve espacio disponible a hacer acotaciones cronológicas más precisas, analizando el alcance seminal de 1956), y analizando ya de forma específica el universo de las ideas y el papel de los intelectuales no podemos obviar una primera constatación, que subraya unas actitudes críticas que podrían sorprender en el contexto de la dictadura. De hecho, la coincidencia temporal del fin de etapa de 1956, que finiquita un cierto tipo de discusiones de los que estaban encaramados al establishment, con el surgimiento de una nueva generación de dirigentes estudiantiles universitarios y la irrupción de una cultura de consumo audiovisual cambió notablemente no sólo el contenido de la vida de las ideas, sino el marco en que desarrollarían. Es posible, como señaló hace años Juan Pablo Fusi ${ }^{13}$, que para la dictadura la disidencia intelectual no fuese inicialmente una gran preocupación habida cuenta de que lanzaba la idea de que en esos años se fraguaba una división entre la cultura académica y una potente cultura de masas, singularmente de la industria musical y televisiva que permitía sostener un control y hegemonía cultural a partir de la potencia de esos medios masivos, al margen de los posibles embates críticos desde la universidad u otros medios tradicionales, con menor capacidad de penetración. De este modo, al antiintelectualismo del «Viva la muerte» lanzado en plena Guerra Civil podría ser sustituido por el desdén hacia los intelectuales por la vía de su superación en la vida pública.

Incluso se sobreponía otro argumento, de naturaleza distinta, pero de efectos coincidentes, a partir de la proclamación del fin de las ideologías que defendía el conspicuo franquista Gonzalo Fernández de la Mora (El crepúsculo de las ideologías, 1965). En este sentido, el desarrollismo en términos económicos y sociales parecía favorecer el impulso de una cultura banal, sustentada en el control eficaz de radio y televisión. Dicho de otra manera, la vía de un incipiente consumo como sustitutivo de la democratización, sin posible confusión terminológica, porque también conviene precisar que modernización no equivale a democratización. La estrategia, más o menos consciente, era clara, pero a pesar de ello el consumo no consiguió «desideologizar» a las minorías sociales más activas. De hecho, ese potencial banal iba más allá del control que ejercía el poder a través de fórmulas clásicas como la censura, y era un tema de preocupación en todo el mundo occidental. Un jovencísimo intelectual crítico, Manuel Vázquez Montalbán, tomó nota de todas las contradicciones que la nueva realidad entrañaba, y puso negro sobre blanco algunas reflexiones sobre ello en Informe sobre la información (1963), en que de forma novedosa se aproximaba a los retos que proponían el papel central en la difusión cultural de la industria discográfica, el cine y en general el mundo audiovisual, que iba más allá del puro control gubernamental. Más adelante, el propio Vázquez Montalbán, que en algunos momentos habló también de «subcultura», analizó las ideas que se desprendian del universo de la canción española, con un tratamiento crítico que provocó el secuestro de su libro Cancionero general (1972), que sucedía a una Crónica sentimental de España (1970), la cual incidía en esa cultura de masas ${ }^{14}$.

En cuanto a las actitudes, la novedad de mayor calado fue la actuación conjunta de núcleos de intelectuales en clave crítica con la política oficial. Ahora se fraguan unos grupos que actúan en un sentido crítico abierto con el poder. Podemos plantearnos

13 Juan Pablo Fusi, Un siglo de España. La cultura, Madrid, Marcial Pons, 1999, p. 109 y ss.

14 En relación a esa cultura de masas son muy interesantes las reflexiones de Vicente SÁnchEz-Bı́sCA, «Las culturas del tardofranquismo», Ayer, núm. n 68, 2007, p. 89-110. 
incluso si era más importante su trabajo teórico o sus posicionamientos claramente políticos y las redes de sociabilidad independientes que se generan totalmente al margen de las instituciones oficiales. A partir de 1962, esos intelectuales estarán constantemente reclamando, contestando al poder, mediante informes, cartas, recogiendo firmas, jugándose el currículum. Como ha descrito Pere Ysàs a partir de informes oficiales ${ }^{15}$, sabemos hasta qué punto esas actitudes causaron sorpresa en el consejo de ministros. El flamante ministro Manuel Fraga no acababa de entender qué sucedía, e intentaba reconducir las primeras acciones con contrarréplicas que no sólo dicen de su carácter, sino del impacto que causaba la novedad.

Ya no tienen protagonismo las viejas querellas orientadas a conseguir cuotas de poder o basadas en controversias sobre cómo orientar el régimen. A partir de las quejas por el tratamiento informativo de las huelgas de Asturias, entre 1962 y 1969 se suman una treintena de iniciativas con suficiente masa crítica de apoyos y que progresivamente emiten opiniones sobre cuestiones más diversas. En realidad, muchas de esas iniciativas entran directamente en el terreno político, ya que cuando reclaman libertad de expresión, libertad de asociación o derecho de huelga están entrando directamente en colisión abierta con la dictadura. Estas acciones van generando un núcleo de «habituales» que van configurando una referencia testimonial decididamente antifranquista, de tal manera que ese sector de intelectuales deviene referencia más allá del mundo profesional, con un sentido claramente político.

En este proceso tienen gran relevancia las redes de sociabilidad que mencionábamos anteriormente, tanto las de tipo formal como las de naturaleza informal. En los sesenta se hacen posibles opciones vetadas en la posguerra. Se consigue, por ejemplo, dar un relativo vuelco a entidades oficiales, como algunos colegios profesionales, que dejan de ser simples organismos administrativos de afiliación obligatoria en relación el ejercicio profesional para enriquecer sus objetivos poniendo atención a la responsabilidad social de los profesionales, a debates sobre implicaciones sociopolíticas de la profesión, ya sea el caso de abogados con la defensa de la libertad de expresión, o de aparejadores y arquitectos en relación a los modelos urbanísticos, o a los ingenieros que proponen discusiones sobre modelo económico y energético. Claro que no es generalizable, pero cuando se produce abre unas posibilidades inéditas, que además conecta con uno de los temas debatidos en todo el mundo, que es precisamente la responsabilidad cívica y política de los profesionales en un mundo en expansión económica, pero al mismo tiempo con cuestionamientos sobre el futuro, cuando sectores de profesionales críticos se interrogan a quién y para qué deben servir, en el marco de las sociedades capitalistas, los conocimientos y habilidades profesionales adquiridas por las élites (Alain Touraine, por ejemplo).

Las publicaciones periódicas ocupan en este período un papel que va más allá de la mera transmisión de ideas ${ }^{16}$. Ya hemos señalado antes que en el contexto de una dictadura el surgimiento de revistas independientes, de nueva planta o como evolución de cabeceras más antiguas, es un hecho trascendente en sí mismo. Pero no sólo se convierten en referencia de una cultura independiente del poder, sino que cumplen otro cometido, de manera más o menos consciente. Se convierten en ámbitos de sociabilidad, en primer lugar porque ponen en relación a equipos de periodistas e intelectuales que se autorreconocen como núcleos

15 Pere Ysàs, Disidencia y subversión. La lucha del régimen franquista por su supervivencia, 1960-1975, Barcelona, Crítica, 2004, especialmente los capítulos 1 y 2.

16 Una interpretación general en Juan Francisco Fuentes, «Prensa y política en el tardofranquismo (1962-1975). La rebelión de las élites", Cercles. Revista d'Història Cultural, núm 6, Universidad de Barcelona, 2003, p. 12-32. 
más o menos cohesionados. Pero además, ese mismo ejercicio se reproduce en relación a los lectores, para los cuáles la adquisición de esas publicaciones se convierte en un símbolo de toma de posición pública y en un sentimiento de pertenencia colectivo, un aspecto que se prolongaba en relación a algunas de las nuevas editoriales que surgieron entonces.

Por último, conviene también evaluar el papel del exilio. De un lado, un exilio que iba desapareciendo, ya fuese por la extinción biológica, ya fuese porque algunos se planteaban si era el momento del regreso, o porque no se habían adaptado mal a sus países de acogida. En cualquier caso, el exilio de 1939 había perdido peso, y entre los intelectuales críticos del «interior» los exiliados republicanos eran fundamentalmente un referente ético, el de los que intentaron resistir al franquismo, pero no eran un referente intelectual o político operativo, porque además la longevidad del exilio los alejaba también generacionalmente ${ }^{17}$. Es decir, sobre todo para los jóvenes críticos del interior los exiliados utilizaban un lenguaje político viejo, del que no podían aprender, precisamente porque para esos jóvenes se sentían atraídos por propuestas con poco eco o inexistentes en los años treinta. Otra cosa, insistimos, es el respeto a los exiliados por su condición de antifranquistas, y su reivindicación ética. Un ejemplo: el regreso de Ortega tiene las repercusiones que son bien conocidas, pero eso no significa que emerja una escuela potente para seguir sus propuestas culturales. Y el intelectual doblado de político que era Azaña difícilmente podía ser un referente para jóvenes impactados por la guerra del Vietnam y los hippies. Azaña les quedaba lejano culturalmente.

También es cierto que esa misma afirmación sería menos cierta en algún otro caso, como por ejemplo Josep Ferrater Mora, que de hecho es un rara avis porque su juventud le impedía tener obra antes de 1939, y había comenzado a producir en el exilio. Al margen del interés de la dictadura por esconder todo ese legado, se había producido un cambio evidente en los temas de interés. Otra cuestión es el surgimiento de un exilio de nueva base, que se genera a partir de los sesenta con jóvenes activistas que huyen de la represión franquista y se convierten en nuevos exiliados, pero que están en total sintonía política y generacional con la realidad crítica del «interior». De manera parecida, sin vínculo con el viejo exilio de 1939 , también ayudaba a esa masa crítica la editorial Ruedo Ibérico ${ }^{18}$, creada en Paris en 1961.

\section{Entre la democracia y la revolución}

La evolución cultural y política mundial, los cambios estructurales que experimentaba el pais y las nuevas opciones para el desarrollo del trabajo cultural (editoriales, revistas...) en el contexto dictatorial fueron forzadas al máximo por los sectores emergentes, ante la práctica desaparición del mundo cultural oficial ${ }^{19}$, que disponía de todos los resortes pero era incapaz de ofrecer una vía de enganche mínimamente atractiva a las nuevas generaciones ${ }^{20}$. En estas circunstancias la cuestión central era ya el discurso. El desengaño de algunos

$17 \mathrm{Al}$ margen de la extensa literatura sobre el exilio, recientemente Jordi GRACIA propone una nueva mirada al debate sobre la vigencia del exilio en A la intemperie. Exilio y cultura en España, Anagrama, Barcelona, 2010.

18 La peculiaridad de esa experiencia a través de su alma mater en Albert Forment, José Martinez: la epopeya de Ruedo ibérico, Barcelona, Anagrama, 2000.

19 Aunque se refiere especialmente a la traducción politica de ese proceso es interesante el planteamiento de Ismael SAZ, «Mucho más que crisis políticas: el agotamiento de dos proyectos enfrentados», Ayer, núm. 68,2007, p. 137-163.

20 Es curioso constatar como Gonzalo Fernández de la Mora, en un artículo de 1964 sobre el pensamiento español necesita tomar nombres del exilio como Garcia Bacca o Eduard Nicol para poder hablar de 
con el régimen, incluso porque no era fascista (Ridruejo), se traducía en antifranquismo. También tenía la misma consecuencia la escasa cintura que había mostrado la dictadura con las iniciativas más transgresoras surgidas de su propio seno, como los jóvenes de Laye y otros casos similares.

Todo eso era antifranquismo, reacción contra la dictadura, pero no necesariamente un discurso democrático. Esa es una cuestión compleja y polémica ${ }^{21}$, que debe entenderse ante la necesidad vital de politización de los intelectuales y ante el auge de todo lo social, con unos intelectuales que buscan el reconocimiento de los núcleos obreros más activos, en un proceso de enorme influjo del marxismo y cuando también el catolicismo comprometido con la realidad se hace más social. Es en este contexto en el que debe estudiarse el discurso de la intelectualidad antifranquista, en relación como mínimo con tres preguntas: ¿hasta qué punto la oposición al franquismo se fundamentaba en una reivindicación de la experiencia democrática de la Segunda República? ¿hasta qué punto la labor de los intelectuales se relacionaba con los partidos de la oposición? ¿hasta qué punto la democracia era una reivindicación instrumental o finalidad en sí misma? En realidad pienso que son más importantes los interrogantes que una resolución con vocación concluyente, ya que las respuestas requerirían de un espacio y unas matizaciones que no son factibles en este trabajo. No obstante ello, sí que se pueden apuntar algunas reflexiones.

En relación a la primera cuestión, ya hemos apuntado al referirnos al exilio las dificultades para vincular los discursos de los años treinta y los de la década de 1960. En este sentido, que los jóvenes más dinámicos de los sesenta reaccionaran al discurso oficial franquista no significaba que comulgaran con el relato de los derrotados, sino que optaban por abrir nuevas vías de interpretación del pasado y de proyección futura. Jordi Solé Tura escribió en sus memorias cuatro líneas esclarecedoras de esas circunstancias:
Con la distancia todo aquel movimiento puede parecer una fiebre de adolescentes, pero en realidad era un estallido de energías que no tenian puntos de referencia en nuestro país y los buscaban donde podian, sin demasiados elementos para poder distinguir entre la realidad y la que nos presentaban como tal, entre la necesidad de dar forma y contenido general a nuestra propia batalla y la estrechez de nuestras posibilidades inmediatas ${ }^{22}$.

Por lo que respecta a los vínculos entre intelectuales disidentes y partidos de la oposición, la actitud militante de muchos de esos intelectuales no debe llevarnos a un inmediato correlato con militancia partidaria, ni a olvidar que en algunas situaciones de tensión la adscripción intelectual añadía un elemento de desconfianza, como se puso de relieve en el célebre caso de Semprún. Por otro lado, es muy dificil calibrar justamente el valor que se daba a un concepto de democracia que parecía necesario adjetivar siempre. El reiterado uso de términos como democracia real, democracia formal, democracia popular, etc., denotaba la resistencia a hablar de democracia sin más, o de democracia liberal. Teniendo en cuenta el clima intelectual internacional, parece que la reivindicación de una democracia liberal no gozaba de suficiente atractivo, y si fijamos la atención en los títulos que publicaban las editoriales antifranquistas observamos unos catálogos mucho más interesados en los grandes referentes del pensamiento marxista, como los que editaba por ejemplo Ariel

\footnotetext{
la buena salud de la filosofia española. Véase Panorama español contemporáneo. XXV años de paz, Madrid, Ediciones de Cultura Hispánica, 1964.

21 Una panorámica con autores franquistas y antifranquistas en Javier MuÑoz Soro, «Los apellidos de la democracia. Los intelectuales y la idea de democracia durante el franquismo (1939-1975)n, Cercles. Revista d'Història Cultural, núm. 14, Universidad de Barcelona, 2011, p. 55-81.

22 Jordi Sole TurA, Una historia optimista. Memorias, Madrid, Aguilar, 1999, p. 220-221.
} 
Quincenal, que no tanto en la recuperación de la tradición liberal. Además, otro elemento favorecería esta tendencia, como es la mayor permisividad de la censura en la segunda mitad de los sesenta en relación a la política internacional.

\section{Una nota final sobre el caso catalán}

Naturalmente, la mayor parte de las cuestiones planteadas hasta aquí tienen vigencia para analizar las bases con las que los intelectuales catalanes abordaron los años sesenta. Claro está que vivian en una sociedad que se transformaba estructuralmente, también atendían al fenómeno migratorio, aunque mayoritariamente desde la perspectiva de la inmigración, y poco significativamente como emigración; también vivían los albores de la sociedad de consumo, con un fuerte componente urbano, etcétera. Y claro está que en una sociedad más desarrollada el consumo cultural se fue convirtiendo en una variable notable, con un decidido impulso a la industria editorial o los más limitados en el campo audiovisual. También se dio un gran impulso a revistas independientes, se manifestó con fuerza la contestación universitaria y se consiguió que algunos colectivos profesionales y sus colegios tomaran un compromiso con el país real, fenómenos todos ellos en que destaca la juventud de la mayoría de sus protagonistas. Todo ello permitiría ahora extenderse en este proceso y en sus nombres propios ${ }^{23}$.

Sin embargo, lo que significa una aportación específica es la reconstrucción de la cultura catalana que se llevó a cabo en aquellos años y que, para algunos de sus protagonistas, era una Nova Renaixença que habría empezado a fines de los cincuenta. Para valorar su significado debemos retrotraernos, aunque sea telegráficamente, a 1939. La implantación del franquismo conllevaba la voluntad de hacer desaparecer la reivindicación catalanista, tanto en su vertiente cultural como en la política. En relación a la política no había dudas ni confusiones. Contrariamente, en cuanto a la cultura el poder franquista distinguió entre folklore y cultura rural, y cultura moderna con implicaciones de proyecto nacional catalán. En cuanto a la primera se mostró progresivamente permisivo con las sardanas, e incluso con un teatro claramente anticuado. Por eso los primeros libros que permitió publicar en catalán debían estar escritos en catalán prenormativo, para dar sensación de reliquia. En cambio, se prohibían obras modernas y los ensayos, y más todavía las traducciones de lenguas extranjeras al catalán.

Jaume Vicens Vives con su Noticia de Catalunya (1954) marca un hito en un cambio de tendencia, cuando tímida y lentamente empiece a plantearse una interpretación sobre la Cataluña moderna. Es significativo el correlato de esa obra con las más tardías de Joan Fuster, Nosaltres els valencians (1962) e incluso la de Josep Melià, Els mallorquins (1967), reflexiones sobre los territorios catalanohablantes que partían de una interpretación histórica, pero que pretendían influir en su presente. Esas reflexiones y las nuevas apuestas más ambiciosas, como Edicions 62 (la primera editorial en catalán dedicada prioritariamente al ensayo), o la revista Serra d'Or (dependiente del monasterio de Montserrat y con un consejo de redacción claramente orientado a la izquierda), no pasaron desapercibidas a las autoridades, que volvieron a plantearse si era posible deslindar cultura y política catalanistas.

23 Una panorámica genérica de este proceso en Carles SANTACANA, «Noves idees i praxi cultural en una societat en canvi sota la dictaduras, en Josep SANTESmases y Ramon Arnabat (eds.), 1960-1980. Transicions i canvis a les terres de parla catalana. Actes del VIII congrés de la CCEPC, Cossetània/ CCEPC, Valls, 2012, p. 61-77. 
Las discusiones secretas del Consejo Nacional del Movimiento son muy esclarecedoras de esas nuevas circunstancias ${ }^{24}$. ¿Qué hacer ante la progresiva presencia de una cultura surgida de forma independiente de los canales oficiales, que podría fluir bajo la etiqueta regional, pero de la que se sospechaba que podía tener otras implicaciones? Las respuestas más inteligentes desde la perspectiva franquista pasaban por integrar en clave regional ese empuje cultural, marcando una línea roja con las posibles interpretaciones políticas. De otra manera, favorecer una cultura regional e impedir que los mismos materiales construyeran una cultura nacional, que era la pretensión catalanista. Más allá de esos debates, que se materializaron en 1962, el régimen siguió actuando de la misma manera, en todo caso modulando en cada momento la combinación precisa entre prohibiciones e ignorancia.

El desdén oficial hacia la cultura catalana precipitó que ésta fuera materia reservada exclusivamente a los núcleos de la oposición, de manera que esta vía favoreció la integración de catalanismo y antifranquismo. Y ahí es donde toman sentido múltiples iniciativas, desde un clandestino Congrés de Cultura Catalana, desarrollado entre 1961-1964, en que los jóvenes recogían el testigo de los mayores, a revistas y proyectos amplísimos, como la Gran Enciclopèdia Catalana (1969) o el encierro de intelectuales en Montserrat (1970), con motivo del proceso de Burgos, al que se sumaría por ejemplo un joven Mario Vargas Llosa que materializa la presencia latinoamericana de aquellos años en Barcelona. Fue en ese contexto en el que se experimentaría un rico diálogo entre intelectuales catalanes y castellanos, con diversos coloquios a partir de 1964, números especiales de revistas madrileñas y polémicas de nivel, como la que sostuvieron Julián Marías y Maurici Serrahima.

En cualquier caso, lo más significativo sería la existencia de un cierto mínimo común denominador catalanista que se iría construyendo a lo largo de los sesenta, pero que naturalmente no podía basarse en la unanimidad, como fueron demostrando agrias polémicas, como la que vivió Josep Pla en relación al Premi d'Honor de les Lletres Catalanes o la que provocó la publicación de Catalanisme i revolució burgesa (1967), de Jordi Solé Tura. Dos casos aparentemente muy distintos, pero que a la postre remitían a la extrema politización de la actividad cultural. En definitiva, reivindicación cultural, catalanismo y antifranquismo irían de la mano hasta la misma transición, y se encarnaron en un proyecto de grandes dimensiones, el Congrés de Cultura Catalana celebrado entre 1975 y 1977, que plasmaba ese mínimo común denominador y que vinculaba tradición, análisis de la realidad y proyecto de futuro, en un modelo que sólo tenía sentido por la especial vinculación entre cultura y política que hemos intentado simplemente esbozar.

24 Véase Carles Santacana, El franquisme $i$ els catalans. Els informes del Consejo Nacional del Movimiento (1962-1971), Catarroja, Afers, 2000. 